\title{
СОЦИОКУЛЬТУРНАЯ КОМПЕТЕНЦИЯ КАК ФАКТОР УСТОЙЧИВОСТИ ФОРМИРОВАНИЯ ЗНАНИЙ
}

\section{SOCIO-CULTURAL COMPETENCE AS A STABILITY KNOWLEDGE FACTOR}

I. Ivanilova

E. Yurkevich

Summary: The article proposes methodological provisions describing training sessions from the perspective of the author's understanding of the culture of communication. Authors shows the peculiarities of the impact of socio-cultural competence as a factor that contributes to the stability of the formation of students ' knowledge, their ability to effectively carry out intercultural communication in the professional sphere. Emergence of a synergetic effect shows that determines the increase in the effectiveness of education is possible if the student owns not only the language means of expression, his interests correspond to the system of spiritual values in the traditions and realities of the country of the language being studied.

Keywords: training sessions; information resources; communication culture; negative feedback and stability of knowledge formation; positive feedback and synergetic effect; interests; conditions for improving the effectiveness of education; spiritual values of the studied language country.
Иванилова Ирина Викторовна

старший преподаватель, Московский государственный технический университет имени Н.Э. Баумана

ivivanilova@bmstu.ru

Юркевич Евгений Владимирович

д.m.н., профессор, г.н.с., Институт проблем управления им. В.A. Трапезникова РАН, Yurkevitch.evgenij@yandex.ru

Аннотация: Предложены методологические положения характеризующие учебные занятия с позиций авторского понимания культуры коммуникаций. Показаны особенности воздействия социокультурной компетенции как фактора, способствующего устойчивости формирования знаний студента, его способности эффективно осуществлять общение в профессиональной сфере. Показано, что появление синергетического эффекта, определяющего повышение эффективности образования, возможно если студент владеет не только языковыми средствами выражения информации, но его интересы соответствуют системе духовных ценностей в традициях и реалиях страны изучаемого языка.

Ключевые слова: учебные занятия; информационные ресурсы; культура коммуникаций; отрицательная обратная связь и устойчивость формирования знаний; положительная обратная связь и синергетический эффект; интересы; условия повышения эффективности образования; духовные ценности страны изучаемого языка.

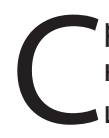

реди важных характеристик современной экономики России сегодня выделяется актуальность интенсификации технологий образования, существенно влияющих на развитие хозяйственного комплекса страны. Будем полагать, что одним из основных условий перехода жизни общества к технологиям 4.0 является формирование информационной среды, вомногом определяемой компетенциями специалистов $[1,2]$. Важной особенностью такой среды является создание эффективных каналов коммуникаций.

В качестве базового постулата определим: воспринятая слушателем информация является его информационным ресурсом; знанием этот ресурс становится после его структуризации данным слушателем по важности. Различие в оценках важности является одной из существенных причин различий в знаниях у каждого из слушателей. Таким образом, будем полагать, что процесс обучения - это научение технологиям, а процесс образования - это формирование личности, сочетающей профессиональные знания и наличие моральных качеств, определяющих целеполагание его деятельности.

Анализ особенностей применения современных технологий показал сходство приемов и средств их реали- зации вне зависимости от страны производства. В то же время конкурентоспособность продукции из различных стран обеспечивается отличиями в эксплуатационных характеристиках продукции этих компаний. Во многом такие отличия определяются культурой производства. Формирование культуры межличностных коммуникаций на производстве должны заполнить учреждения образования. В предлагаемом рассмотрении культура производства материальных (и нематериальных) благ должна формироваться уже на стадии образования, т.е. формирования культурной личности.

В данном случае культуру коммуникаций слушателя предлагается рассматривать как характеристику его заинтересованности в восприятии материала, предлагаемого преподавателем. В более общем виде культура коммуникаций проявляется в виде заинтересованности субъекта (личности) в положительной реакции его окружения (людей, природы) на его действия или высказывания. Например, рюкзак в узком проходе автобуса, вытянутые ноги в метро, или грязь на скамейке в парке - это частные проявления уровня культуры коммуникаций.

Традиционно, для построения образовательного процесса рекомендовалась объектная парадигма $[3,5]$. 
Она ориентировала преподавателей на максимизацию количества излагаемого материала. В соответствии с предлагаемым пониманием культуры коммуникаций актуально принятие субъектной парадигмы. Она обуславливает постановку задачи максимизации знаний каждым из слушателей. Исходя из такого положения, определяется важность культуры преподавания не только специальных учебных курсов, но и целенаправленное формирование идеологии слушателей, определяемое изучением русского языка и других гуманитарных дисциплин.

Вторым важным свойством культуры коммуникаций между участниками проведения учебных занятий является её влияние на устойчивость формирования знаний. Если рассматривать целенаправленное взаимодействие преподавателя и студента как систему формирования знаний, то станет ясно, что устойчивость такой системы определяется глубиной обратной связи, т.е. уровнем культуры преподавателя, определяющей желание, чтоб его поняли слушатели, и уровнем культуры студента, определяющей желание понять преподавателя.

Повышенное внимание к межличностным отношениям в образовательном учреждении определяет третье свойство культуры коммуникаций - возможность появления синергетического эффекта.

Согласно выводам работы [4], необходимым условием образования синергетического эффекта является сходство целей каждого из участников образовательного процесса; достаточным условием является сходство интересов этих участников. Будем полагать, что интерес - это отображение цели участника образовательного процесса на количество (и вид) ресурсов, которые ему требуются для её достижения.

Например, имеются преподаватель и слушатель.
Пусть они оба стремятся к максимизации успеваемости, т.е. необходимое условие выполнено. Однако синергетического эффекта не возникло из-за несоответствия условию достаточности. Не образовалась взаимоподдержка, так как одному для повышения эффективности преподавания желательно творческое начало, а другому требуется увеличение материальных стимулов.

В целом, важной особенностью ускорения темпов технологического развития является его гармонизация с темпами обновления информации, которой должны владеть выпускники образовательных учреждений $[2,6]$. В этой связи весьма актуальным является изучение современных тенденций в привлечении иностранных партнеров на российский рынок и особенностей формирования транснациональных деловых отношений.

Реализация названной тенденции на международном рынке предполагает необходимость интенсификации в изучении русского языка в мировом сообществе, и в том числе преподавание курса «Русский язык как иностранный». Важной особенностью образования синергетического эффекта при взаимодействиях в системе «Учитель - Ученик» является раскрытие положительной обратной связи, т.е. если повышение раскрытия духовных потенций в мышлении преподавателя будет ускорять личностно-духовный рост ученика, то и повышение духовных потенций в мышлении ученика будет ускорять личностно-духовный рост преподавателя.

Названные условия во-многом определяют формирование гармоничного психологического климата в образовательном учреждении. В конечном итоге они определяют возможность устойчивого выпуска специалистов как интеллектуальных личностей, обладающих глубокими знаниями и имеющих государственный уровень мышления.

\section{ЛИТЕРАТУРА}

1. Пассов Е.И., Кибирева Л.В., Колларова Э. Концепция коммуникативного иноязычного образования. СПб.: Златоуст, 2007. 199с.

2. Загвязинский, В.И. Педагогическая инноватика: проблемы стратегии и тактики: монография [Текст] / В.И. Загвязинский, Т.А. Строкова. - Тюмень: Издательство Тюменского государственного университета, 2011. - 176 с.

3. Баева Л.В. Информационная эпоха: метаморфозы классических ценностей: монография. Астрахань, 2008. 218 с.

4. Юркевич Е.В. Механизмы обеспечения функциональной надежности в образовании - М.: ФГУП «Производственно-издательский комбинат ВИнитИ», 2008,68 c.

5. Иванилова И.В., Юркевич Е.В., Крюкова Л.Н. Механизмы использования технологий дополненной реальности в образовании // Современное педагогическое образование № 1, 2020, С. 84-90.

6. Абламейко С.В., Казаченок В.В., Мандарик П.А. Современные информационные технологии в образовании // Материалы Международной научной конференции «Информатизация образования - 2014: педагогические аспекты создания и функционирования виртуальной образовательной среды». Минск, 2014. С. 7-13.

() Иванилова Ирина Викторовна (ivivanilova@bmstu.ru), Юркевич Евгений Владимирович (Yurkevitch.evgenij@yandex.ru).

Журнал «Современная наука: актуальные проблемы теории и практики» 